\title{
Meio ambiente e desenvolvimento na região metropolitana de Porto Alegre: uma abordagem a partir do espaço rural.
}

Osmar Tomaz de Souza ${ }^{2}$ Augusto Mussi Alvim ${ }^{3}$ Letícia Hoppe ${ }^{4}$ Luzihê Martins ${ }^{5}$ Giórgia Pasquetti ${ }^{6}$

\section{Resumo}

A gestão do meio ambiente em regiões metropolitanas representa um grande desafio à política ambiental, pois a elevada aglomeração de pessoas e atividades nas metrópoles cria um cenário propício ao aprofundamento dos problemas ambientais. Em especial, as áreas rurais das áreas

I Resultados parciais de Pesquisa apoiada pela Fundação de Amparo à Pesquisa do Estado do Rio Grande do Sul (FAPERGS).

2 Professor da Pontifícia Universidade Católica do Rio Grande do Sul (PUC-RS) - Porto Alegre, Brasil e do Programa de Pós-Graduação em Economia (PPGE). Doutor em Desenvolvimento e Meio Ambiente pela Universidade Federal do Paraná. É autor de artigos publicados nas revistas Economia e Sociedade, Indicadores Econômicos FEE, Ensaios FEE, Ambiente e Sociedade, Estudos Sociedade e Agricultura, Economia E Tecnologia, Análise, Desenvolvimento e Meio Ambiente, entre outras.E-mail: osmar.souza@pucrs.br.

3 Professor da Pontifícia Universidade Católica do Rio Grande do Sul (PUC-RS) - Brasil. Doutor em Economia pela Universidade Federal do Rio Grande do Sul. É autor de artigos publicados nas revistas E3 Journal of Agricultural Research and Development, Economia E Tecnologia, Ensaios FEE e Revista de Economia e Sociologia Rural, entre outras. E-mail: augusto.alvim@pucrs.br.

4 Professora na Escola de Negócios da Pontifícia Universidade Católica do Rio Grande do Sul (PUC-RS) - Brasil. Doutora em Engenharia e Tecnologia de Materiais pela Pontifícia Universidade Católica do Rio Grande do Sul. Assessora a direção do Instituto do Meio Ambiente da PUC-RS na elaboração de projetos no âmbito da economia ambiental.E-mail: leticia.hoppe@pucrs.br.

5 Professora nos cursos de Administração e Ciências Contábeis da Faculdade Cenecista de Osório (FACOS) Osório, Brasil. Mestre em Economia do Desenvolvimento pela Pontifícia Universidade Católica do Rio Grande do Sul. Faz consultoria e treinamento nas áreas de Responsabilidade Social Empresarial e Gestão Ambiental. E-mail: luzihe.martins@yahoo.com.br.

6 Graduada em Economia, vinculada à Pontifícia Universidade Católica do Rio Grande do Sul (PUC-RS) Brasil. E-mail: giorgia.pasquetti@gmail.com. 
Meio ambiente e desenvolvimento na região metropolitana de Porto Alegre: uma abordagem a partir do espaço rural | Osmar Tomaz de Souza - Augusto Mussi Alvim - Letícia Hoppe - Luzihê Martins - Giórgia Pasquetti

metropolitanas que têm sido relegadas ao plano secundário, embora representem a maior parte da área física dessas regiões e possuam grande diversidade de funções. O objetivo neste trabalho é refletir sobre esses temas com base na Região Metropolitana de Porto Alegre, no estado do Rio Grande do Sul. Para tanto, são analisados: a) a dinâmica e as funções do rural; b) as principais políticas de desenvolvimento e ambientais que nele incidem; c) os embates sobre as políticas de desenvolvimento regional neste contexto.

Palavras-chave: Desenvolvimento regional. Desenvolvimento rural. Meio ambiente. Região metropolitana de Porto Alegre.

\section{Introdução}

A gestão do meio ambiente em regióes metropolitanas tem representado um grande desafio à política ambiental e ao poder público, dada a grande afluência populacional e a concentração de atividades econômicas nesses espaços. Não há como negar que a elevada aglomeração de pessoas e atividades nas metrópoles cria um cenário propício ao aprofundamento dos problemas ambientais.

Em especial, há um aspecto crucial da gestão ambiental nas áreas metropolitanas que tem sido relegado ao plano secundário: as áreas rurais metropolitanas. Essas áreas são representativas tanto pela sua área física (pois, em geral, representam a maior parte da área total dos municípios) quanto pela diversidade de funções e atribuições a ela delegadas. Dentre tais funções, destacam-se não somente a produção agropecuária como também a conservação ambiental e a oferta de outros bens e serviços associados ao ambiente rural, como os recursos hídricos, turismo, lazer, moradia, etc.

Há três ou quatro décadas, o espaço rural era visto, sobretudo, como um espaço de produção de alimentos, de geraçáo de divisas e depositário de mão de obra potencial para o desenvolvimento urbano e industrial. $\mathrm{Na}$ atualidade, observa-se uma multiplicação de suas "funçóes", especialmente porque é nas áreas rurais que se encontra boa parte das parcelas do território que a sociedade deseja ver preservado.

Essa mudança de percepção sobre o rural afeta especialmente aquelas áreas rurais inseridas dentro de regióes metropolitanas como a de Porto Alegre, cujo espaço rural passa a merecer atenção por se constituir em áreas de preservação do meio ambiente e da paisagem, de turismo e lazer, de moradia e também de produção de alimentos, dentre outras "funçôes". Além do mais, trata-se de uma área física que representa $50 \%$ da área total da Regiáo Metropolitana de Porto Alegre (GRANDO; MIGUEL, 2002). É nesse contexto que o espaço 
rural metropolitano vem ganhando relevância quando se trata da gestão do espaço e da preservação do meio ambiente.

Isso se verifica porque as políticas de desenvolvimento regional no Brasil - especialmente aquelas que lidam com o desenvolvimento em espaços considerados mais "urbanos", caso das regióes metropolitanas -, têm dado pouca atenção aos espaços rurais enquanto lócus de produção e, sobretudo, de proteção e preservação ambiental. É sabido que nas políticas de modernização da agricultura brasileira dos anos 1970/1980 a questão ambiental não se colocava enquanto prioridade ou preocupação. $\mathrm{O}$ objetivo era a mudança da base técnica - num processo de apropriaçáo crescente pela indústria de elementos do ciclo produtivo agrícola - e pela transformação das formas de gestão, com a preeminência do modelo empresa. A mudança da base técnica estava atrelada a um "pacote tecnológico" que previa a motomecanização, os produtos químicos como fertilizantes e defensivos (identificada como "Revolução Verde") e a pesquisa genética para seleção e melhoramento das espécies animal e vegetal.

Em linhas gerais, a ideia de desenvolvimento que estava por trás daquelas políticas vislumbrava a transição, a passagem, a ruptura entre um passado "arcaico" e um futuro "moderno". O pensamento dicotômico que fundamenta essa visão se espacializava no rural (agrícola) e no urbano (industrial), segundo o pressuposto de que o novo mundo era urbano e o velho era rural, em função dos espaços que historicamente eram base dos modelos societários em expansão e em declínio. A modernização da agricultura avançava nesse sentido. Diante das perspectivas da urbanização societária geral, tratava-se de artificializar a agricultura - que liberava crescentemente a produção de alimentos da sua base natural-rural e de seus componentes e agentes sociais arcaicos (FERREIRA, 2002). Com isso, os aspectos físico-naturais eram considerados apenas quando representassem limites potenciais ao desenvolvimento da produção. E, nesses casos, as novas tecnologias dariam conta de "corrigir" o meio ambiente e viabilizar a produção.

Os limites da visão dicotômica do rural, da sua invisibilidade no contexto metropolitano de Porto Alegre, bem como as implicaçóes da tentativa de fixação de um modelo padrão de desenvolvimento rural, estimularam a pesquisa cujos resultados parciais são apresentados neste trabalho. Esta pesquisa vem sendo desenvolvida em perspectiva com outra realizada na Região Metropolitana de Curitiba (RMC) pelo grupo de pesquisa "Dinâmicas 
Meio ambiente e desenvolvimento na região metropolitana de Porto Alegre: uma abordagem a partir do espaço rural | Osmar Tomaz de Souza - Augusto Mussi Alvim - Letícia Hoppe - Luzihê Martins - Giórgia Pasquetti

Rurais, Agricultura e Sustentabilidade" e que enfoca o rural daquela região. $\mathrm{Na}$ Regiáo Metropolitana de Porto Alegre (RMPA), o objetivo é compreender as dinâmicas, as especificidades e o papel do rural no contexto dos processos de desenvolvimento regional, tendo como contraponto as políticas públicas e sua capacidade (ou não) de atender ao conjunto do território em questão.

Em outras palavras, os objetivos neste trabalho são: a) caracterizar a agricultura e o rural da RMPA, sua dinâmica socioeconômica recente e diversidade de funçôes, contrapondo-os à evidência que é habitualmente conferida ao processo de urbanização e industrialização regional; b) identificar as políticas de desenvolvimento regionais e rural, bem como ambientais cuja ação tem implicaçóes para as dinâmicas produtivas e náo produtivas rurais; (c) confrontar as particularidades relacionadas à regulação do espaço rural e do seu papel no desenvolvimento da regiáo metropolitana de Porto Alegre, reconhecida como uma das maiores aglomeraçóes urbano-industriais do país.

\section{Notas sobre o papel ou as funções do agrícola e do rural}

A última década do século passado alterou o debate sobre o desenvolvimento e, em especial, sobre o desenvolvimento rural. Em primeiro lugar, porque se evidenciaram os limites de um modelo de desenvolvimento que tratava as diferentes regióes como sendo passíveis de homogeneização, como se estas estivessem totalmente aptas a incorporar tecnologias e práticas padronizadas. Em segundo lugar, porque aquelas políticas ampliaram e reforçaram ainda mais a heterogeneidade dos espaços regionais, os quais dificilmente poderiam ser apreendidos pelos instrumentos de políticas de desenvolvimento tradicionais. Por último, e não menos importante, porque emergiu a percepção sobre a importância dos espaços de produção agropecuária como espaços capazes de produzir não apenas produtos primários, como também uma série de "novos" produtos, ligados principalmente aos aspectos ambientais.

Em síntese, passa-se a falar de espaços rurais multifuncionais, sobre os quais incidem as mais variadas demandas sociais, com destaque para a produção de alimentos, a preservação da natureza e da biodiversidade, o turismo e o lazer, a manutenção do patrimônio sociocultural ligado às tradiçóes, aos hábitos e aos costumes, etc.

Os estudos sobre o tema das múltiplas funções do rural ou sobre as diferentes ruralidades como formas de expressão se proliferaram a partir da 
década de 1990. É o que sinalizam, por exemplo, os trabalhos de Moreddu (2003); Hervieu (2002); Carron e Torre (2003); Perrier-Cornet (2002); Pingault (2004); SFER (2003); Nidedu (2004), os quais enfocam, sobretudo, a multifuncionalidade da agricultura a partir das negociaçóes da Organizaçáo Mundial do Comércio e das realidades europeia e francesa.

Igualmente refletem a nova realidade e a complexidade do rural, trabalhos como os de Ferreira e Brandenburg (1998); Veiga (2002); Wanderley (2000 e 2001); Schneider (2003); Carneiro e Maluf (2003), dentre outros. No tema do espaço rural inserido em regióes metropolitanas, destaca-se o trabalho de Souza e Brandenburg (2010), que analisam as mudanças na relação sociedade/ natureza e suas implicaçóes para a gestáo do desenvolvimento regional/rural nas mesmas.

Embora não sejam trabalhos que enfocam o rural no contexto de regióes metropolitanas, o que se observa na grande maioria dos autores citados é que eles expressam em maior ou menor grau algumas (novas) demandas sociais que impóem à gestáo do espaço rural uma série de conflitos. Exemplos desses conflitos são aqueles ligados à(ao): a) necessidade de produção versus a busca de preservação do meio ambiente; (b) busca de preservação ambiental em espaços rurais versus a exploração dos mesmos por atividades turísticas e de lazer; (c) uso de espaços rurais para moradia de pessoas que trabalham nos centros urbanos, e assim por diante. Esse tipo de situação está longe de ser tratada de forma apropriada pelas políticas de desenvolvimento regional, especialmente nas regióes metropolitanas como a de Porto Alegre, visto que essas políticas trazem o viés urbano, ainda que a maior parcela do território consista em áreas rurais.

Nesse contexto, vale destacar o questionamento de Valette (2004, p.1) sobre qual o papel dos territórios rurais "em um mundo em que se fortalece a hegemonia das metrópoles, em que as áreas urbanas concentram a maior parte da população, assim como também concentram as atividades culturais [...]”. Embora a preocupaçáo central dessa autora seja os espaços rurais periurbanos, chama atenção a tese defendida por ela de que tais territórios se constituem em "territórios privilegiados para a emergência de inovaçóes econômicas e sociais". 


\section{Histórico e caracterização da região metropolitana de Porto Alegre}

A RMPA foi criada por lei em 1973 e era composta, inicialmente, por 14 municípios. No início daquela década, a população total regional girava em torno de 1,53 milhão de habitantes. A população urbana representava mais de $92 \%$ do total, enquanto que a populaçáo rural equivalia a 7,91\% do total, conforme se observa na Tabela 1 . O destaque em relaçáo à população rural ficava por conta dos municípios de Viamáo, onde ela equivalia a $82,8 \%$ do total, Guaíba (40,16\%), Gravataí (30,93\%) e Sapiranga (30,89\%).

A produção hortigranjeira, segundo o Plano de Desenvolvimento Metropolitano, editado em 1973, era considerada como uma atividade altamente importante para a agricultura metropolitana, pela proximidade do mercado consumidor, também com a possibilidade de proporcionar alimentos adequados às pequenas propriedades familiares existentes na regiáo.

Tabela I - População residente urbana e rural nos municípios da RMPA 1970

\begin{tabular}{lrrrrr}
\hline Município & Urbana & \multicolumn{1}{c|}{ Rural } & \multicolumn{1}{c}{ Total } & \% pop rural \\
\hline Alvorada & 39.656 & 666 & 40.322 & 1,65 \\
Cachoeirinha & 29.955 & 1.047 & 31.002 & 3,38 \\
Campo Bom & 14.771 & 1.846 & 16.617 & 11,11 \\
Canoas & 149.183 & 4.547 & 153.730 & 2,96 \\
Estancia Velha & 7.732 & 1.184 & 8.916 & 13,28 \\
Esteio & 32.895 & 1.702 & 34.597 & 4,92 \\
Gravataí & 36.237 & 16.225 & 52.462 & 30,93 \\
Guaíba & 20.153 & 13.527 & 33.680 & 40,16 \\
Novo Hamburgo & 81.235 & 4.129 & 85.364 & 4,84 \\
Porto Alegre & 869.730 & 15.815 & 885.545 & 1,79 \\
São Leopoldo & 62.990 & 1.443 & 64.433 & 2,24 \\
Sapiranga & 11.336 & 5.066 & 16.402 & 30,89 \\
Sapucaia do Sul & 41.116 & 626 & 41.742 & 1,50 \\
Viamão & 11.425 & 55.018 & 66.443 & 82,80 \\
\hline População Total & 1.408 .414 & 121.139 & 1.531 .255 & 7,91 \\
\hline
\end{tabular}

Fonte: IBGE, Censo Demográfico 1970.

Duas décadas depois, em 1991, a população total da RMPA alcançava 3,2 milhóes de habitantes, sendo que deste total em torno de 5,2\% da população apresentava domicílio rural (METROPLAN, 2008). Naquela década, o número de municípios na regiáo havia aumentado para 22. Durante as décadas de 1990 e 2000, novos municípios foram incorporados, definindo a atual configuração da RMPA, mostrada na Figura 1, abaixo. 


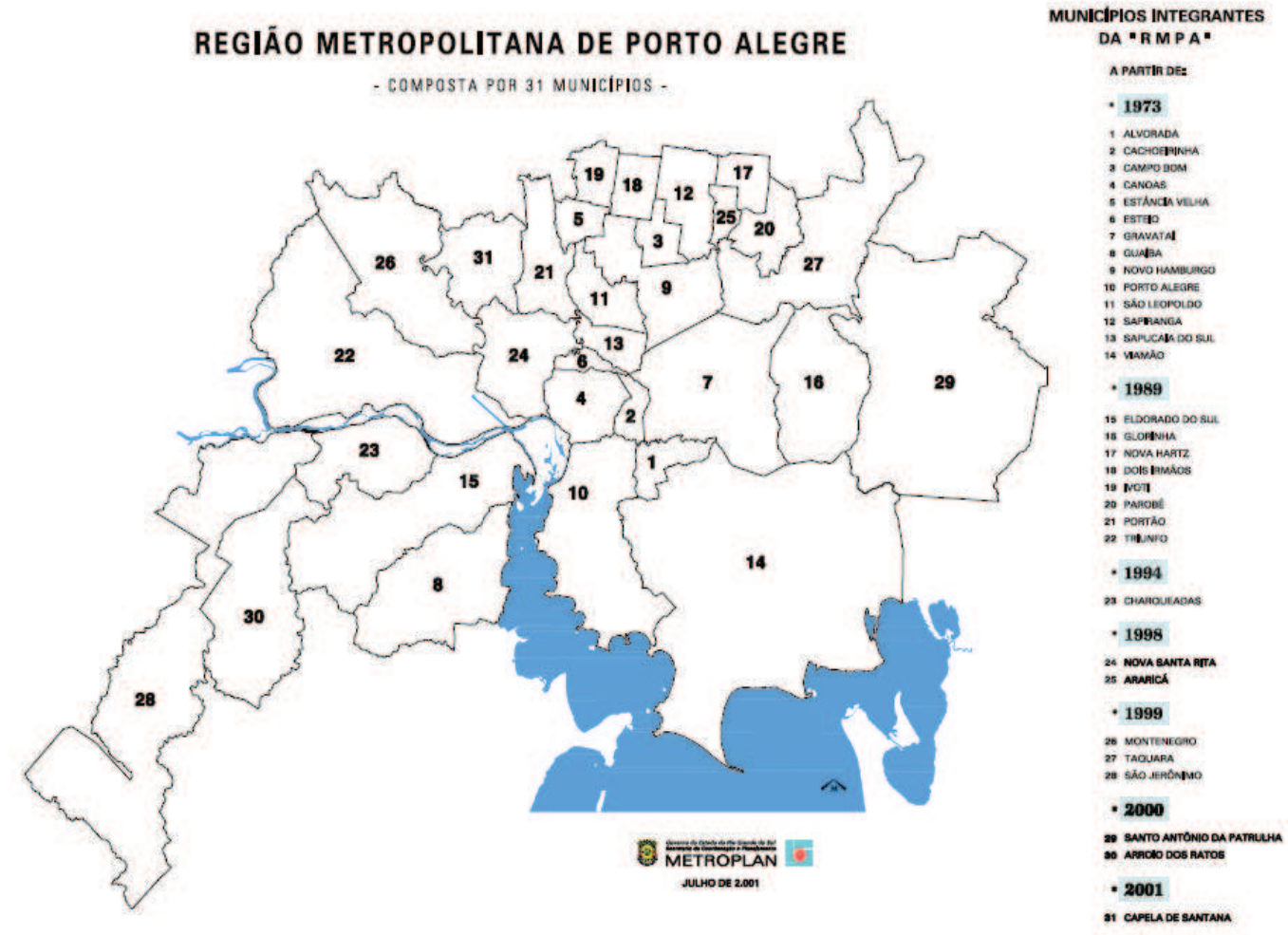

Figura I - Mapa dos municípios integrantes da RMPA e ano de incorporação

Fonte: Metroplan, 2008.

Se tomarmos como base a atual configuração da RMPA e analisarmos sua composiçáo e dinâmica populacional, começa-se a perceber mais claramente a dimensão que o rural ocupa no âmbito regional, especialmente a partir da entrada de novos municípios. A tabela 2 a seguir apresenta a situação domiciliar das populaçóes dos municípios da regiáo no ano de 1991 (incluindo aqueles incorporados posteriormente) e ilustra a afirmação anterior.

O que se observa é que, em relação a 1970, a participação percentual da populaçáa rural se reduziu para 5,2\% (170 mil pessoas no meio rural da região), especialmente diante do incremento populacional urbano de alguns municípios como: Alvorada, Canoas, Gravataí, Novo Hamburgo, São Leopoldo, Sapucaia do Sul, Viamão e a capital Porto Alegre. Entretanto, a análise regional apenas em termos percentuais totais deixa escapar as especificidades municipais, o que aqui é particularmente importante como objeto de análise. Os dados indicam que dentre os 31 municípios da RMPA, oito deles (Ca- 
pela de Santana, Eldorado, Glorinha, Ivoti, Montenegro, Santo Antônio da Patrulha, São Jerônimo e Triunfo) apresentam população rural entre $25 \%$ e $86 \%$ de suas populações totais.

Tabela 2 - População total segundo situação de domicílio nos municpios da RMPA - 1991

\begin{tabular}{|c|c|c|c|c|}
\hline Nome Municipio & $\begin{array}{l}\text { População } \\
\text { Urbana }\end{array}$ & $\begin{array}{l}\text { População } \\
\text { Rural }\end{array}$ & $\begin{array}{l}\text { População } \\
\text { Total }\end{array}$ & $\%$ Pop Rural \\
\hline $\begin{array}{l}1 \text { ALVORADA } \\
2 \text { ARARICÁ }\end{array}$ & 141.881 & 165 & 142.046 & 0,12 \\
\hline 3 ARROIO DOS RATOS & 10.610 & 1.214 & 11.824 & 10,27 \\
\hline 4 CACHOEIRINHA & 87.951 & 244 & 88.195 & 0,28 \\
\hline 5 САМРО ВОМ & 46.481 & 1.395 & 47.876 & 2,91 \\
\hline 6 CANOAS & 270.672 & 8.455 & 279.127 & 3,03 \\
\hline 7 CAPELA DE SANTANA & 4.813 & 2.663 & 7.476 & 35,62 \\
\hline 8 CHARQUEADAS & 24.349 & 407 & 24.756 & 1,64 \\
\hline 9 DOIS IRMAOS & 17.851 & 1.100 & 18.951 & 5,80 \\
\hline 10 ELDORADO DO SUL & 12.480 & 5.223 & 17.703 & 29,50 \\
\hline 11 ESTANCIA VELHA & 26.713 & 1.477 & 28.190 & 5,24 \\
\hline 12 ESTEIO & 70.468 & 79 & 70.547 & 0,11 \\
\hline 13 GLORINHA & 632 & 3.955 & 4.587 & 86,22 \\
\hline 14 GRAVATAI & 167.863 & 13.172 & 181.035 & 7,28 \\
\hline 15 GUAIBA & 73.778 & 9.324 & 83.102 & 11,22 \\
\hline 16 IVOTI & 9.201 & 7.125 & 16.326 & 43,64 \\
\hline 17 MONTENEGRO & 36.917 & 12.182 & 49.099 & 24,81 \\
\hline 18 NOVA HARTZ & 8.121 & 1.892 & 10.013 & 18,90 \\
\hline 19 NOVA SANTA RITA & & & & \\
\hline 20 NOVO HAMBURGO & 201.502 & 4.166 & 205.668 & 2,03 \\
\hline 21 PAROBE & 30.771 & 1.224 & 31.995 & 3,83 \\
\hline 22 PORTAO & 16.445 & 3.044 & 19.489 & 15,62 \\
\hline 23 PORTO ALEGRE & 1.247 .529 & 15.874 & 1.263 .403 & 1,26 \\
\hline 24 SANTO ANTONIO DA PATRULHA & 21.065 & 19.542 & 40.607 & 48,12 \\
\hline 25 SAO JERONIMO & 13.610 & 14.074 & 27.684 & 50,84 \\
\hline 26 SAO LEOPOLDO & 160.358 & 7.549 & 167.907 & 4,50 \\
\hline 27 SAPIRANGA & 52.907 & 5.768 & 58.675 & 9,83 \\
\hline 28 SAPUCAIA DO SUL & 104.486 & 399 & 104.885 & 0,38 \\
\hline 29 TAQUARA & 35.100 & 7.367 & 42.467 & 17,35 \\
\hline 30 TRIUNFO & 9.980 & 7.943 & 17.923 & 44,32 \\
\hline 31 VIAMAO & 156.145 & 13.031 & 169.176 & 7,70 \\
\hline \begin{tabular}{l|l} 
TOTAL RMPA \\
\end{tabular} & 3.060 .679 & 170.053 & 3.230 .732 & 5,26 \\
\hline
\end{tabular}

Fonte: Metroplan, 2008.

Não se trata de minimizar a importância da urbanização e do crescimento populacional nesta situaçáo. Pelo contrário, entre 1970 e 1990, a população urbana regional mais do que dobrou, passando de 1,4 milhão para 3,06 milhôes de pessoas. Sabe-se que isso exige atenção especial no planejamento e nas políticas de desenvolvimento regional. Contudo, não se pode ignorar a dinâmica particular do espaço rural na RMPA.

No caso da dinâmica populacional regional, dois aspectos se evidenciam quanto ao espaço rural e têm repercussáo para as açóes a ele dirigidas: 
a. Nos municípios metropolitanos pode haver um movimento de saída da população rural em direção aos diversos centros urbanos regionais, o que também se configura em outras regióes do Estado; e

b. Esses mesmos municípios (sobretudo suas áreas rurais) podem ser receptáculos da população migrante de outras regióes do estado e mesmo da população urbana que busca estabelecer moradia ou apenas sítios de lazer em áreas rurais próximas das cidades.

Cada um desses dois aspectos têm implicação para as políticas de desenvolvimento regional no que tange aos espaços rurais. Vejamos o que mostram os dados referentes ao ano de 2000, apresentados na Tabela 3.

A despeito da diminuição da população rural total, a confrontação dos dados de 2000 (Tabela 3) com aqueles de 1991 (Tabela 2) mostram um fato interessante: a populaçáo rural em termos absolutos aumentou pelos dados oficiais em mais da metade dos municípios. Isso se verificou em Alvorada (aumento de $265 \%$ da população rural em termos absolutos), Campo Bom (56\%), Capela de Santana (41\%), Charqueadas (132\%), Eldorado do Sul (54\%), Esteio (10\%), Glorinha (11\%), Gravataí (56\%), Nova Hartz (16\%), Parobé (9\%), Portão (59\%), Porto Alegre (151\%), Sapucaia do Sul (135\%), Taquara (32\%), Triunfo (17\%) e Viamão (21\%). Tais dados sinalizam para uma realidade que merece ser investigada, pois se trata de uma dinâmica particular do espaço rural regional e da população que o ocupa dentro dos quadros da RMPA. Embora se trate de uma regiáo que apresenta dados de urbanização crescentes, verifica-se o aumento do número de pessoas residentes no meio rural.

Também cabe observar que vários desses municípios que apresentam elevação da população rural estão localizados no eixo de expansão da malha urbana (Figura 2, a seguir), o que torna este fenômeno ainda mais interessante. Esses são os casos de Esteio, Gravataí, Sapucaia do Sul, Viamão, além da própria capital, Porto Alegre. Isso nos leva a indagar sobre quais são os fatores que estão induzindo ao aumento absoluto das populaçóes rurais mesmo nos municípios em forte processo de urbanização. 
Tabela 3 - População dos Municípios da RMPA por situação de domicílio, 2000.

\begin{tabular}{|c|c|c|c|c|}
\hline Municipios & Pop Total & Urbana & Rural & $\%$ Pop rural \\
\hline Alvorada & 183.968 & 183.365 & 603 & 0,33 \\
\hline Araricá & 4.032 & 3.493 & 539 & 13,37 \\
\hline Arroio dos Ratos & 13.335 & 12.528 & 807 & 6,05 \\
\hline Cachoeirinha & 107.564 & 107.564 & - & - \\
\hline Campo Bom & 54.018 & 51.838 & 2.180 & 4,04 \\
\hline Canoas & 306.093 & 306.093 & - & - \\
\hline Capela de Santana & 10.032 & 6.277 & 3.755 & 37,43 \\
\hline Charqueadas & 29.961 & 29.015 & 946 & 3,16 \\
\hline Dois Irmãos & 22.435 & 22.272 & 163 & 0,73 \\
\hline Eldorado do Sul & 27.268 & 19.242 & 8.026 & 29,43 \\
\hline Estância Velha & 35.132 & 34.367 & 765 & 2,18 \\
\hline Esteio & 80.048 & 79.961 & 87 & 0,11 \\
\hline Glorinha & 5.684 & 1.285 & 4.399 & 77,39 \\
\hline Gravataí & 232.629 & 212.144 & 20.485 & 8,81 \\
\hline Guaíba & 94.307 & 91.956 & 2.351 & 2,49 \\
\hline Ivoti & 15.318 & 13.785 & 1.533 & 10,01 \\
\hline Montenegro & 54.692 & 48.862 & 5.830 & 10,66 \\
\hline Nova Hartz & 15.071 & 12.879 & 2.192 & 14,54 \\
\hline Nova Santa Rita & 15.750 & 11.550 & 4.200 & 26,67 \\
\hline Novo Hamburgo & 236.193 & 231.989 & 4.204 & 1,78 \\
\hline Parobé & 44.776 & 43.439 & 1.337 & 2,99 \\
\hline Portão & 24.657 & 19.818 & 4.839 & 19,63 \\
\hline Porto Alegre & 1.360 .590 & 1.320 .739 & 39.851 & 2,93 \\
\hline Santo Antônio da Patrulha & 37.035 & 23.483 & 13.552 & 36,59 \\
\hline São Jerônimo & 20.283 & 15.611 & 4.672 & 23,03 \\
\hline São Leopoldo & 193.547 & 192.895 & 652 & 0,34 \\
\hline Sapiranga & 69.189 & 65.785 & 3.404 & 4,92 \\
\hline Sapucaia do Sul & 122.751 & 121.813 & 938 & 0,76 \\
\hline Taquara & 52.825 & 43.125 & 9.700 & 18,36 \\
\hline Triunfo & 22.166 & 12.887 & 9.279 & 41,86 \\
\hline Viamão & 227.429 & 211.612 & 15.817 & 6,95 \\
\hline RMPA & 3.718 .778 & 3.551 .672 & 167.106 & 4,49 \\
\hline
\end{tabular}

Fonte: Metroplan, 2008.

Situação semelhante se verifica pela análise da composição do Valor Adicionado Bruto (VAB) dos municípios da regiáo pelos dados disponíveis para o ano de 2003, apresentados na Tabela 4. Para o conjunto da RMPA, a atividade econômica mais importante é a Indústria, que produz 51,2\% do VAB regional, seguida pelos Serviços, com 45,08\% do total. Para a Agropecuária, observamos uma participação de apenas 1,35\%.

Ao visualizarmos as diferentes realidades municipais, a situação é diferente. Municípios como Glorinha, Sáo Jerônimo, Santo Antonio da Patrulha, Arroio dos Ratos e Capela de Santana são ilustrativos, pois indicam outra distribuição. Os três primeiros apresentam participação da Agropecuária no VAB municipal superior a 25\%, e os dois últimos entre 17 e 19\%, respectivamente. Ressalte-se que, à luz desses casos, saímos de uma participação relativa média da Agropecuária no VAB da RMPA de apenas 1,35\% e chegamos a uma participação de 33,7\% para o município de Glorinha. 


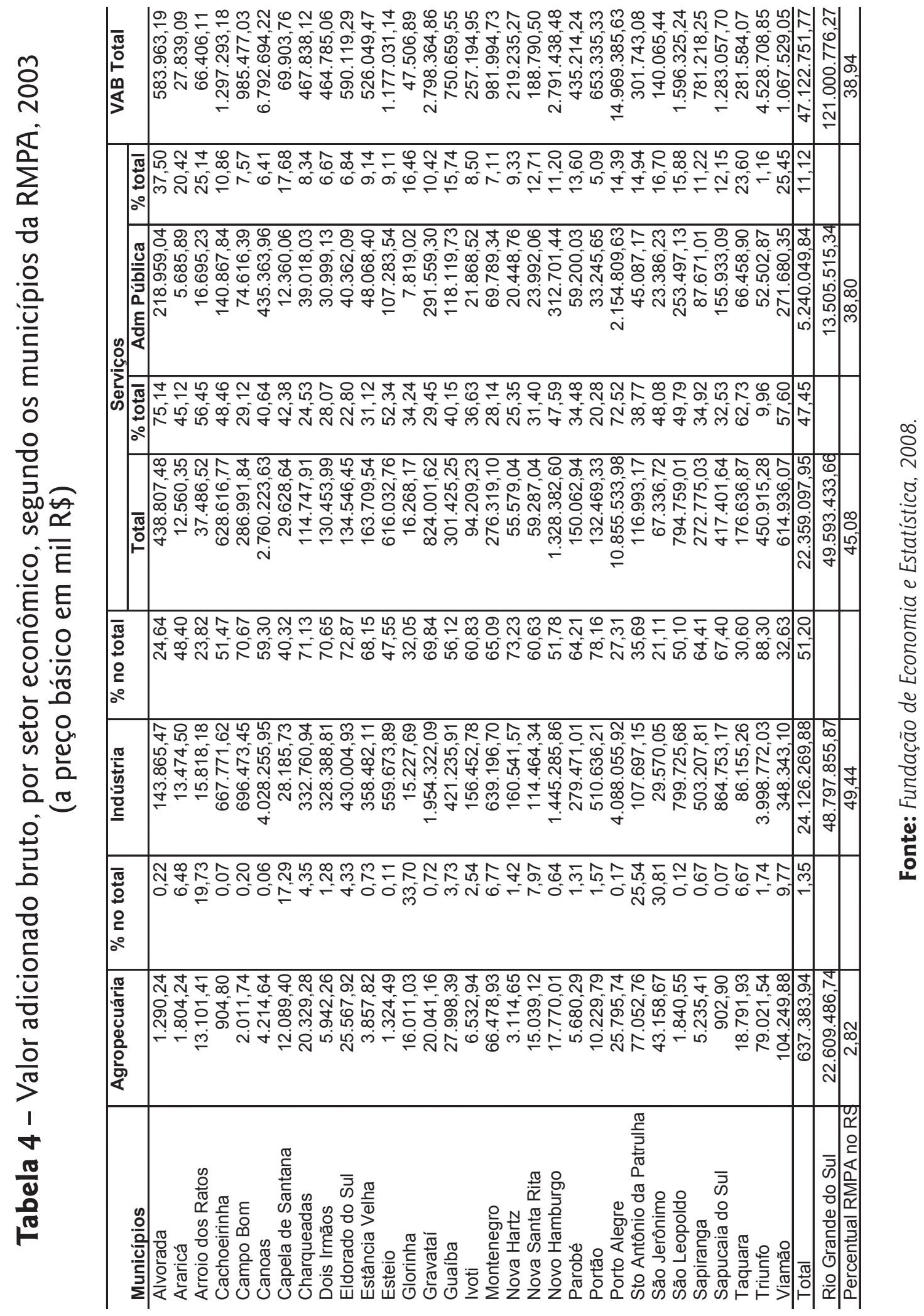




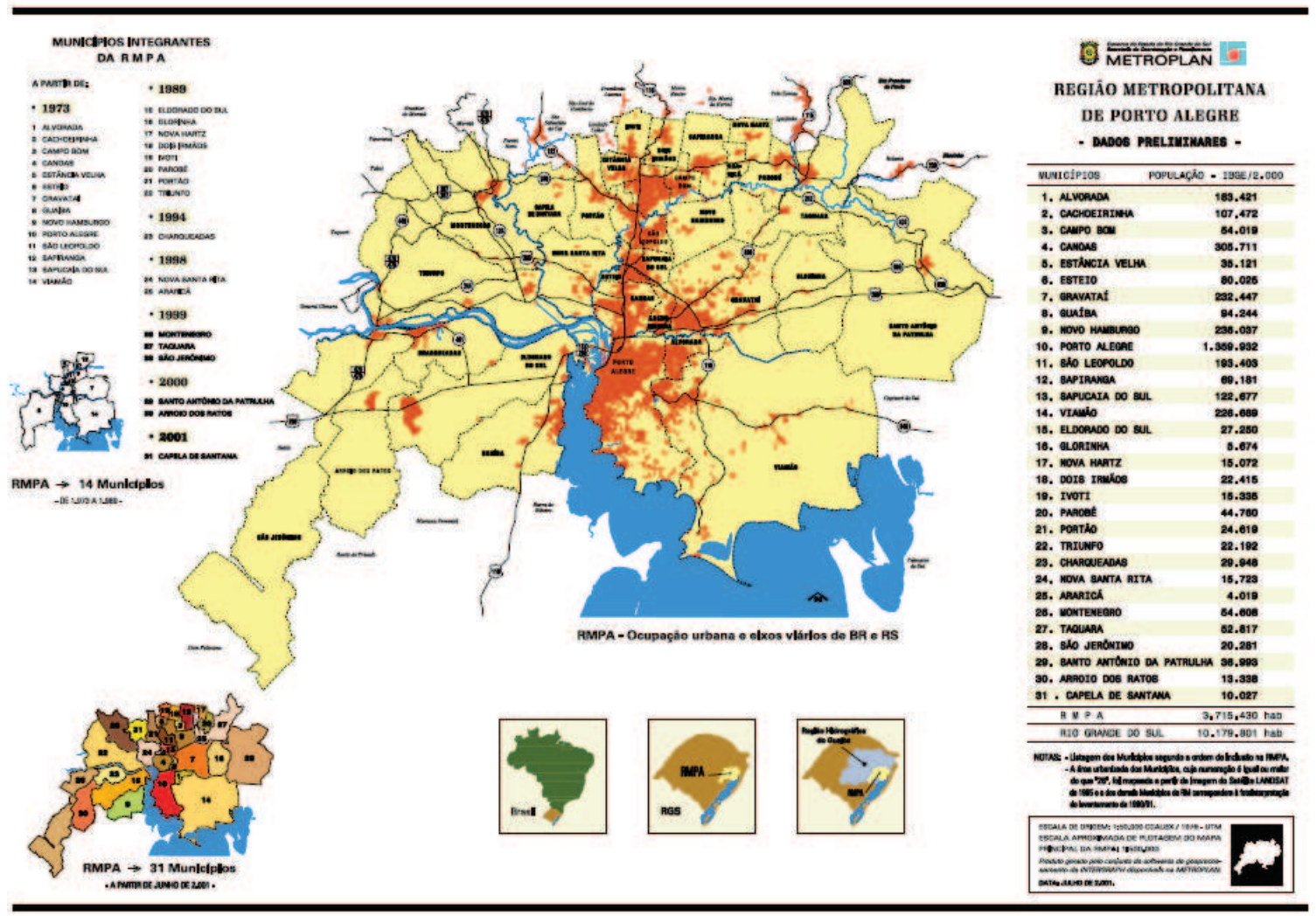

Figura 2 - Mapa de Localização e Ocupação da malha urbana da RMPA 2000

Fonte: Metroplan, 2008.

Tratando-se de planejamento regional e de políticas públicas de desenvolvimento, isso reforça a complexidade que assume o conjunto da RMPA. Ela engloba municípios com diversidade tanto nos seus aspectos demográficos quanto nas suas estruturas produtivas. Além disso, são municípios cujos espaços rurais apresentam relevante atividade agropecuária, conforme se verá adiante, e que estão inseridos no contexto de uma regiáo com grande concentração populacional, representando a quarta maior região metropolitana do país em termos populacionais.

\section{Aspectos do rural e da produção agropecuária da RMPA}

O Plano de Desenvolvimento Metropolitano de Porto Alegre (PDMPA) em 1973 sinalizava que as atividades agropecuárias mais importantes na regiáo eram: a rizicultura, a bovinocultura de corte e leiteira, a avicultura, a olericultura, a fruticultura e a silvicultura (VOLPI, 1980). O mesmo plano apontava ainda que as atividades mais viáveis para a regiáo seriam: a 
olericultura, a fruticultura, a bovinocultura leiteira e a criação de aves. Em linhas gerais, toda essa produção apresentada como "viável" se consistia num tipo de produção adequada aos estabelecimentos de base familiar que geralmente se desenvolvem nos menores estratos de área.

Em 1970, a estrutura fundiária da RMPA se consistia majoritariamente de pequenos estabelecimentos, mesmo com a participaçáo relevante das propriedades acima de 50 hectares, especialmente na área total (Tabela 5).

\section{Tabela 5 - Estrutura fundiária na Região Metropolitana de Porto Alegre, 1970 e 1995.}

\begin{tabular}{|c|c|c|c|c|c|c|c|c|}
\hline \multirow[b]{3}{*}{ Estratos } & \multicolumn{4}{|c|}{1970} & \multicolumn{4}{|c|}{1995} \\
\hline & \multicolumn{2}{|c|}{ Estabelecimentos } & \multicolumn{2}{|c|}{ Área } & \multicolumn{2}{|c|}{ Estabelecimentos } & \multicolumn{2}{|c|}{ Área } \\
\hline & Número & $\%$ & Hectares & $\%$ & Número & $\%$ & Hectares & $\%$ \\
\hline menos de 10 & 4.432 & 41,30 & 16.926 & 4,00 & 3.700 & 38,50 & 17.058 & 4,60 \\
\hline 10 a menos de 20 & 2.248 & 21,00 & 31.011 & 7,20 & 2.403 & 25,00 & 33.292 & 9,00 \\
\hline 20 a menos de 50 & 2.496 & 23,30 & 74.566 & 17,40 & 2.266 & 23,60 & 66.492 & 17,90 \\
\hline 50 a menos de 100 & 853 & 8,00 & 56.579 & 13,20 & 638 & 6,60 & 42.979 & 11,60 \\
\hline 100 a menos de 1000 & 593 & 5,50 & 158.804 & 37,00 & 561 & 5,80 & 142.853 & 38,50 \\
\hline mais de 1000 & 52 & 0,50 & 91.141 & 21,20 & 34 & 0,40 & 68.632 & 18,50 \\
\hline Sem declaração de área & 45 & 0,40 & & & 7 & 0,10 & & \\
\hline & 10.719 & & $429.027,00$ & & 9.609 & & 371.307 & \\
\hline
\end{tabular}

Fonte: Volpi, 1980; IBGE, 1995-1996.

Os estabelecimentos com até 20 hectares representavam $62,3 \%$ do total, mas ocupavam apenas $11,2 \%$ da área total regional. No outro extremo, os estabelecimentos com área superior a 100 hectares representavam $6 \%$ do total de estabelecimentos e ocupavam 58,2\% da área total na RMPA. Tais dados sinalizam para a concentração fundiária que se verificava na região à época.

No ano de 1995, a principal mudança na estrutura fundiária regional se deu no estrato de área inferior a 10 hectares, que apresentou uma redução do número de estabelecimentos; de 4432 para 3700. Contudo, a participação relativa dos estabelecimentos com até 20 hectares (soma dos dois primeiros estratos) aumentou para 63,5\% do número total de estabelecimentos e 13,6 $\%$ da área total. Por seu lado, nos maiores estratos de área (estabelecimentos com mais de 100 hectares), mantém-se a concentração verificada em 1970; estes representam $6,2 \%$ do total de estabelecimentos e $57 \%$ da área total.

Apesar de o diagnóstico de "viabilidade" do PDMPA náo indicar a produção de grãos, em 1995, os dados da Fundação de Economia e Estatística (FEE, 2008) indicavam que, mesmo com a importância da produção de frutas 
(como laranja e pêssego), a produção de grãos (especialmente arroz, milho e soja) ocupava mais de 54 mil hectares na RMPA.

Pela própria condição geográfica, a área utilizada com a produção de grãos, principalmente o arroz, se concentrava mais nos municípios próximos ao Delta do Jacuí e ao Guaíba, casos de Triunfo, Nova Santa Rita, Eldorado do Sul, Guaíba e Viamáo. A produção de milho se distribuía por praticamente toda a região, sempre em pequenas áreas, com destaques para os municípios de Triunfo, Nova Santa Rita, Glorinha, Eldorado do Sul, Dois Irmáos e Estância Velha. Já a produção de frutas (pêssego, laranja, melancia, melão e goiaba) era destaque em Triunfo, Porto Alegre, Portáo, Novo Hamburgo e Nova Santa Rita (METROPLAN, 1999).

O tema do turismo em áreas rurais também está presente em municípios da RMPA. O turismo rural constitui-se em uma atividade que une a exploração econômica a outras funçóes como a valorização do ambiente rural e da cultura local que, não raras vezes, são alguns de seus atrativos principais. Em outras palavras, o turismo rural incorpora aquilo que podemos identificar como as "múltiplas" funçôes da agricultura e do rural.

Oficialmente, vários municípios da região estáo incluídos nos roteiros de turismo rural do Estado. Dentre eles, destacam-se Viamáo (Casas Fazenda), Gravataí (Fazendas Turísticas), Montenegro e Novo Hamburgo (Hospedagens Coloniais) e Glorinha (Programas Especiais de Turismo Rural) (SETUR, 2008).

\section{Principais aspectos ambientais da RMPA}

Além das questôes ligadas à ocupação e ao uso do solo pela urbanização e pelas atividades industriais e agropecuárias, destacadas anteriormente, no quesito ambiental a RMPA comporta uma vasta gama de funçóes. A existência de pelo menos uma dezena de Unidades de Conservação é prova disso. $\mathrm{Na}$ Regiấo encontram-se tanto unidades federais quanto estaduais, municipais e particulares. Merecem destaque os seguintes: Parque Estadual do Delta do Jacuí, Parque Estadual Rondinha, Parque Estadual de Itapuá, APA Rota do Sol, APA Banhado Grande, as Terras Indígenas Cantagalo e Capivari, além das muitas Reservas Particulares distribuídas pela RMPA (FEPAM, 2008). 
Se, por um lado, a existência das unidades de conservação evidencia a atuação da política ambiental e a preocupaçáo com o tema, por outro, ilustram a complexidade da questáo da ocupação do espaço pela urbanizaçáo versus conservação ambiental. Unidades de conservação tendem a trazer a reboque tensóes e conflitos na relação ambiente e sociedade; numa região metropolitana isso tende a ganhar maior dimensão.

Em relação às atividades agropecuárias, há que ressaltar que a atividade arrozeira, a mais importante lavoura na regiáo, se desenvolve no sistema irrigado, o que pressiona o ambiente tanto pelo uso da água quanto pelo uso de defensivos e agroquímicos.

A RMPA vem sendo marcada pela rápida expansão da ocupação populacional e das atividades econômicas, mas se constitui num território com características geofísicas e ambientais bastante particulares. Ela é o desembocadouro de vários rios, como Rio Caí, Rio dos Sinos, Rio Gravataí e o próprio Rio Jacuí, cujo Delta se desenrola num vasto conjunto de ilhas, além do próprio Lago Guaíba que banha vários municípios da região e segue rumo ao sul do Estado.

A atividade industrial regional é uma das mais importantes do país, mas, além destas, as próprias atividades agropecuárias desenvolvidas na regiáo (orizicultura, olericultura, fruticultura, dentre outras) são intensivas em insumos químicos e podem representar fatores de pressão adicional sobre o meio físico. Â luz dessas observaçóes sobre o espaço rural regional, investigaram-se quais são as principais políticas de desenvolvimento regional, rural e ambiental atualmente em execução na região. $\mathrm{O}$ próximo item é dedicado a esse tema.

\section{Políticas de desenvolvimento regional, rural e ambiental na RMPA}

No âmbito da RMPA, o órgão responsável pela gestão urbana e pelo planejamento regional é a METROPLAN. Embora náo seja responsável apenas pelo desenvolvimento integrado na regiáo de Porto Alegre ${ }^{7}$, a METROPLAN foi instituída no ano de 1974 como um órgáo de apoio técnico do Conselho Deliberativo da RMPA (METROPLAN, 2008).

7 A METROPLAN também é responsável pela gestão de outras aglomerações urbanas do Estado: Aglomeração Urbana do Nordeste, Aglomeração Urbana do Sul e Aglomeração Urbana do Litoral Norte. 
Meio ambiente e desenvolvimento na região metropolitana de Porto Alegre: uma abordagem a partir do espaço rural | Osmar Tomaz de Souza - Augusto Mussi Alvim - Letícia Hoppe - Luzihê Martins - Giórgia Pasquetti

Os destaques de projetos para a regiáo apontados pela METROPLAN nos últimos anos são ligados ao "Programa Asfalto de Ruas" e "Construção de Galpóes de Reciclagem de Lixo" (METROPLAN, 2008). Na área ambiental, a referência é ao "Plano Diretor de Resíduos Sólidos na RMPA", o "Laboratório de Educação Ambiental" e o apoio ao planejamento e à gestão dos recursos hídricos. Em termos específicos do rural regional, não foram identificados projetos específicos.

No que tange à política ambiental, a regulação regional se dá basicamente pela política nacional de meio ambiente e seus instrumentos. Na esfera estadual, o programa mais importante identificado foi o Pró-Guaíba - Programa para o Desenvolvimento Ecologicamente Sustentável e Socialmente Justo da Região Hidrográfica Guaíba. Trata-se de um programa criado através de Decreto no final de 1989 e que sofreu várias modificaçóes desde entáo. O seu objetivo é a melhoria das condiçôes ambientais da regiáo hidrográfica do Rio Guaíba, a qual envolve 251 municípios do Estado e extrapola os limites da RMPA. De qualquer forma, o programa identifica como principais problemas ambientais a serem sanados: a contaminação de esgoto doméstico, emissão de efluentes líquidos e gasosos, disposição de resíduos sólidos urbanos e industriais, destruição de ecossistemas significativos, mineração e escassez de água (FEPAM, 2010). Não é feita referência às atividades rurais da região.

No que trata especificamente do Desenvolvimento Rural, o principal programa disponível para atender à agropecuária regional identificado foi o Programa Nacional de Fortalecimento da Agricultura Familiar (PRONAF), que é um programa do Governo Federal e cuja gênese data do ano de 1994, quando foi criado pelo Governo Federal o Programa de Valorização da Pequena Produção Rural - PROVAP.

As mudanças recentes no PRONAF parecem evidenciar tanto a apropriaçáo quanto o reconhecimento das múltiplas dimensôes e "funçôes" que a agricultura possui ou está habilitada a cumprir. Sabe-se que este não é um programa que tem como prioridade espaços rurais metropolitanos, como o rural da RMPA que aqui se investiga. Ainda assim, foi o único programa de desenvolvimento que atende ao rural regional e que comporta de forma relativamente explícita os aspectos relacionados à conservação ambiental, o que se evidencia por linhas como o Pronaf Florestal (que estimula o "adequado manejo dos recursos naturais"); o Pronaf Agroecologia (que visa à conversão produtiva para a produção agroecológica) e o Pronaf Turismo Rural, que pode 
ser entendido, em última instância, como o reconhecimento do rural como espaço diferenciado, capaz de ser consumido na forma de turismo e lazer.

Ainda ligado ao desenvolvimento do turismo, identificamos algumas instituiçôes e linhas de crédito de apoio ao turismo rural com incidência na RMPA, como as linhas de crédito disponibilizadas pela Caixa Econômica Federal (Investgiro Caixa Turismo e Proger, BNDES Automático e FINAME) e o Caixa RS - Fomento Econômico e Social.

Não se tem elementos suficientes para analisar o alcance desses instrumentos na RMPA, mas pode-se afirmar que alguns deles são importantes tendo em vista a diversidade e a heterogeneidade do rural da regiáo. Sáo programas ou linhas de crédito que podem incorporar vários aspectos das mudanças do olhar sobre o rural que podem se constituir em vetores de muita tensão nos diferentes espaços rurais (produçáo, preservação, moradia, turismo, lazer, depositário de recursos ambientais, expansão da malha urbana, etc.).

Entretanto, destaca-se a ausência de políticas e programas de desenvolvimento construídos no âmbito regional que possa contemplar a totalidade do espaço físico da RMPA, rural mais urbano. Especificamente nos quadros da METROPLAN é que tal ausência chama mais atenção, dado que ela é o órgão de gestáo urbana e regional do Governo do Estado para a região. Ao que parece isto evidencia a relativa invisibilidade dos espaços rurais no que tange às políticas públicas de desenvolvimento regional. Isto é verdade principalmente nos casos em que os espaços rurais parecem estar situados "à margem dos processos de urbanizaçáo" de uma maneira mais evidente, o que os relega à condição de territórios periféricos.

\section{Considerações finais}

O cenário da RMPA e do seu espaço rural expressa um pouco das transformaçóes ocorridas na visão do agrícola e do rural brasileiro nas últimas décadas. Tais transformaçóes afetam tanto as formas de funcionamento das unidades produtivas agrícolas quanto a forma de se pensar as políticas de desenvolvimento. Sejam elas de ordem econômica, produtiva, social, política, cultural, etc., a verdade é que são, em parte, resultantes da própria ação de políticas públicas e atualmente colocam estas últimas num novo patamar de debates e de construção. 
Meio ambiente e desenvolvimento na região metropolitana de Porto Alegre: uma abordagem a partir do espaço rural | Osmar Tomaz de Souza - Augusto Mussi Alvim - Letícia Hoppe - Luzihê Martins - Giórgia Pasquetti

Entretanto, as políticas de desenvolvimento, especialmente no caso da regiáo metropolitana de Porto Alegre, não parecem convergir para o novo quadro de demandas socioeconômicas e ambientais às quais o agrícola e o rural estão sujeitos.

Se a multiplicidade das funçóes da agricultura e do rural ganhou corpo a partir de mudanças na relaçáo entre sociedade e natureza (e se expressa no conceito de "desenvolvimento sustentável"), o desafio para as políticas públicas de desenvolvimento regional continua sendo como se apropriar desse novo olhar sobre o mundo rural, a partir da definição de objetivos mais amplos (mais multifuncionais).

Os bens agrícolas, que compunham o elemento central das funçóes clássicas da agricultura no processo de desenvolvimento, passam a se associar a um amplo conjunto de bens complexos, portadores de características e atributos diversos, que implicam aspectos cognitivos, imagens, símbolos, valores, etc. que os identificam muito mais como bens públicos ou coletivos do que como bens privados. Os impactos de tal mudança de percepçáo sobre o agrícola e o rural na reproduçáo da agricultura na regiáo metropolitana sáo diversos, sobretudo porque revela o conflito de modelos, de valores, de culturas e uma renovação global da visão de agricultura e de rural.

A nova imagem da agricultura e do rural obriga as políticas públicas a revisar suas lógicas e orientaçóes, o que parece ser mais demorado nos contextos em que o urbano e as atividades a eles associados estáo mais evidenciada do que as atividades rurais. É aí que o rural aparenta ser mais "invisível” às políticas de desenvolvimento.

$\mathrm{Na}$ mesma linha, cabe observar que o estudo da ação ou a avaliação destas políticas precisa mudar de foco; discussóes acerca da evolução dos gastos, número de produtores, produção, produtividade ou comércio exterior devem ser combinadas a aspectos sociais, ambientais e culturais para que se possa contemplar de forma mais adequada o caráter multifuncional da produção agrícola ou do espaço rural. Isso é especialmente relevante para o caso da RMPA, diante da evolução recente do seu meio rural evidenciada neste trabalho.

Quando o rural passa a ser visto no seu conjunto e na sua relação com a regiáo metropolitana e com o restante da sociedade, as fronteiras destas políticas passam a ser questionadas, visto que, ao enfatizar a produçáo, determinada política pode entrar em conflito com outras políticas que privilegiem as ques- 
tôes ambientais, sociais, culturais, etc. Nesse sentido, há implicaçóes tanto para a orientação das políticas - sobretudo no tratamento parcial que estas dão ao regional e ao rural - quanto para o estudo da eficiência e da eficácia do agrícola (e do rural).

Especificamente na relação entre o desenvolvimento regional e o meio ambiente, fica claro que o espaço rural merece centralidade. É neste que se encontram as maiores áreas físicas de interesse de preservação, ele é depositário de boa parte dos recursos hídricos e das amenidades valorizadas pelo mundo urbano. Mais que isso, o aumento da populaçáo rural, das atividades turísticas e de outras atividades produtivas no rural metropolitano de Porto Alegre expressam o novo rol de demandas que o conjunto da sociedade a ele imputa. Esse conjunto de observaçóes reforça a percepção de que tais espaços rurais se colocam como tema complexo e privilegiado na agenda de pesquisas sobre o desenvolvimento rural e regional no país.

\section{Referências}

BRASIL. Censo Demográfico. Rio de Janeiro: IBGE, 1970.

BRASIL. Censo Agropecuário. Rio de Janeiro: IBGE, 1995/1996. CD-ROM

CARNEIRO, M. J.; MALUF, R. S. (Org.). Para além da produçáo - multifuncionalidade e agricultura familiar. Rio de Janeiro: MAUAD, 2003.

CARRON, A.; TORRE, A. Les conflits d'usages dans les espaces ruraux: une analyse économique. In: PERRIER-CORNET, P. (directeur d'ouvrage). À qui appartient l'espace rural?. La Tour d'Aigues (France): L'aube Datar, 2002.

FEE - FUNDAÇÃO DE ECONOMIA E ESTATÍSTICA. Estatísticas FEE. Disponível em: <http://www.fee.rs.gov.br/>. Acesso em: abr. 2008.

FEPAM - FUNDAÇÃO ESTADUAL DE PROTEÇÃO AMBIENTAL HENRIQUE LUIS ROSSLER. Disponível em: <http://www.fepam.rs.gov.br/>. Acesso em: abr. 2008.

FEPAM - FUNDAÇÃO ESTADUAL DE PROTEÇÃO AMBIENTAL HENRIQUE LUIS ROSSLER. Programas e projetos: pró-guaíba. Disponível em: <http://www.fepam.rs.gov.br/>. Acesso em: 03 ago. 2010.

FERREIRA, A. D. D. Processos e sentidos sociais do rural na contemporaneidade: quais especificidades do caso brasileiro? In: ENCONTRO NACIONAL DE ESTUDOS RURAIS E URBANOS, 29.,2002, Sáo Paulo. CERU/USP, 2002. 
Meio ambiente e desenvolvimento na região metropolitana de Porto Alegre: uma abordagem a partir do espaço rural | Osmar Tomaz de Souza - Augusto Mussi Alvim - Letícia Hoppe - Luzihê Martins - Giórgia Pasquetti

FERREIRA, A.D.D. \& BRANDENBURG, A. (Org.). Para pensar outra agricultura. Curitiba: Ed. UFPR, 1998.

GRANDO, M. Z.; MIGUEL, L. de A. Agricultura na regiáo metropolitana de Porto Alegre aspectos históricos e contemporâneos. Porto Alegre: Editora da UFRGS /FEE, 2002.

HERVIEU, B. Espace multiple. In: PERRIER-CORNET, P. (directeur d'ouvrage). À qui appartient l'espace rural?. La Tour d'Aigues (France): L'aube Datar, 2002, p. 5-9.

METROPLAN - Fundaçáo de Planejamento Metropolitano e Regional. Aspectos do setor agropecuário na regiáo metropolitana de Porto Alegre. Porto Alegre: METROPLAN, 1999.

METROPLAN - Fundação de Planejamento Metropolitano e Regional. Disponível em: <http:// www.metroplan.rs.gov.br/>. Acesso em: jul. 2008.

MOREDDU, C. Multifonctionnalité: un aperçu des travaux de l'OCDE. Économie Rurale. Paris, SFER, n. 273-274, janvier-avril 2003, p.103-120.

NIEDDU, M. Penser la multifonctionnalité agricole en reconnaissant le pluralisme des approches économiques. In DELORME, H. La politique agricole commune, anatomie d'une transformation . Presses de Sciences Po, Paris, 2004, p.183-201.

PINGAULT, N. La multifonctionnalité: caractéristique ou objectif pour l'agriculture? In DELORME, H. La politique agricole commune, anatomie d'une transformation. Presses de Sciences Po, Paris, 2004, p.183-201.

PERRIER-CORNET, P. (directeur d'ouvrage). À qui appartient l'espace rural?. La Tour d'Aigues (France): L'aube Datar, 2002.

SCHNEIDER, S. A pluriatividade na agricultura familiar. Série Estudos Rurais. Porto Alegre: UFRGS Editora, 1998.

SETUR - Secretaria de Estado do Turismo do Rio Grande do Sul. Disponível em: <http://www. turismo.rs.gov.br/>. Acesso em: 21 jul. 2008.

SFER. Économie Rurale. La multifonctionalité de l'activité agricole. Paris: SFER/CIRAD/ CNASEA/INRA, p. 273-274, janvier-avril 2003.

SOUZA, O.T. de; BRANDENBURG, A. A quem pertence o espaço rural? As mudanças na relação sociedade/natureza e o surgimento da dimensáo pública do espaço rural. Ambiente \& Sociedade. Campinas: ANPPAS, v. 13, n. 1, p. 51-64, jan-jun/2010. 
VALETTE, E. A economia rural periurbana ou inovação em periferia: o caso de montpellier (França). Interaçóes (Campo Grande). v. 5, n.8, p. 9-19, mar. 2004.

VEIGA, J.E. Cidades imaginárias. Campinas: Editora Autores Associados, 2002.

VOLPI, J. C. O abastecimento de produtos hortigranjeiros na regiáo metropolitana de Porto Alegre. Porto Alegre: METROPLAN, 1980.

WANDERLEY, M. N. B. A emergência de uma nova ruralidade nas sociedades modernas avançadas: o rural como espaço singular e ator coletivo. Estudos Sociedade e Agricultura. Rio de Janeiro: UFRRJ/CPDA, n.15, p. 87-145, outubro 2000.

A ruralidade no Brasil moderno. Por um pacto social pelo desenvolvimento rural. IN; GIARRACA, N.(compiladora) Uma nueva ruralidad em America Latina? Buenos Aires: CLACSO-ASDI, 2001, p. 31-44.

\section{Environment and development in metropolitan region of Porto Alegre: an approach from rural areas}

\section{Abstract}

Environmental management in metropolitan regions is one of the biggest challenges to the environmental policy, especially from the huge concentration of people and economic activities. But more than that, there is a particular issue to be managed in those regions: the rural areas. In some of the Brazilian metropolitan regions, such as Metropolitan Region of Porto Alegre (RMPA), the rural areas are representative in physical terms and also from its diversity of functions. The main objective of this paper is to question and to better understand such issues taking the Rural of the Metropolitan Region of Porto Alegre, Rio Grande do Sul. To reach such objective we analyze: a) the dynamic and the functions of agriculture and rural in RMPA; b) the main public policy instruments for its development and; $c$ ) the controversies concerning the rural development policies.

Key words: Regional Development. Rural development environment. Metropolitan Region of Porto Alegre. 